microscopically, when no trace of any other salt or atom, but the tripeds alone, existed, and their total disappearance on the production of new forms. First, the tripeds being dried on olass, and covered with another plate of glass, without any trace of salt or other matter, or of remaining humidity, and exposed to the sum, th $\Rightarrow y$ assume beautitul arborescent forms, resembling shrubs and trees-a volta-magnetic action. Secondly, when allowed to subside, as a sediment, in water, the specdy production of numerous living animalculae, of round and oroid forms, which did not previously exist; for electrical aeticn then occurs, which is the action of election, resulting from the supervention of carbon from deposition rest or rust, (roost, Du.;) and thirdly, when the water is poured off, and this sediment permitted to dry, it assumes the appearance of earthy matter, full of small fibrils or tendrils, like fine hairs, resembling a delicate turf or peat, none of which, except the tripeds, existed previously in the water, but all evincing so many imitations of this subtle clement of life, in which sense regarding it from such a combination of eridence, together with the local exemption from cholera, it may be justifiable to suggest it as bing, very probably, an antidote to that morbid inflence in the earth, air, and water, as well as in the fluids of the system, which interesting development of this subject was purely owing to a series of accidents, but particularly to the accidental exposure of the atoms to the sun.

The infusoria being found in fog, rain, and snow, $I$ am disposed to attribute their origin to atmospheric combinations of hydrogen and nitrogen, the clements of ammoniacal gas, acted on by the magnetic or solar heat and light, yielding a primitive alkaline basis* for the action of the other vitalizing agent, the oxyenic acidities of the earth, air, and water. And taking those data inclusively, they seem to suggest nitrates and carbonates of ammonia and iron, either as prophylactics, or remedies against the prevailing epidemic.

I trust I may here briefly pursue this subject, in the way of further illustration, and assuming that this object, the alkaloid criped, is the elementary principle of motion, extension, or heat, hydrogen, I associate its vitalization, when carburetted, with oxygen, the element of cold, the instrument of cohesion, and agent of sensibility, voltaism, which envelops and restrains the radiating and magnetic power of heat, and which is the sesult of a mutual attraction butween the respective elements, siydrogren and oxygen, according to ordained creative laws.

When the two powers are combined in an uniform ratio and isolated position, a spheroidal figure is produced; when mydrogen, the element of heat, predominates, as a main constituent, an ovoid figure, or an angular and crystalline body is produced ly dispersion of the motor radiation by cohesive restraint; when the element of motion exists in a still higher ratio, the ramification of branches occurs in plants, and of $1 \mathrm{mbs}$ in animals, being the onerations of magnetic extension, more or less diffused. And in alternating parthenogenesis by fission or germination, those processes occur according to the fluctuating ascendancy of the motor or sentient power; the motor, or magnetic, producing fission, (Psalm xxix. 9,) and the sentient or voltaic coercing germination, being the relative antaxonisms of extension and cohesion, or literally, of the opposite properties of the agent of heat-hydrogen, and of the agent of cold-oxygen. The principle of alternation being, in one instance, the result of the exhanstion of rigour consequent mon the action of expenditure or emanation, inducing increased concentration of sensibility, suppressive of action; and in the other instance, the accumulation of vigour during its suppression, in its turn diffuses sensibility, and subdues it to partition, being the two agents and springs of the resilience of vital action, which argument, applied to the present figure of the earth, is indicative of a subsequent elongation of the poles, or transition from a sentient to a motor constitution; paradoxically, abative of rotation; but is the result of a recoil or metastasis of the motor power, from the equatorial region of magnetic projection and dispersion, to the axal line of magnetic extension, inducing subsidence of periphery and of rotation.

Oxygen is represented by the anuulus, and hydrogen by the triped, the emblems of elastic involution and motion, and in combination form the emblem of corporeal life, embodied in a sphere-a volta-magnetic combination, the agent of creation solely concerned in the production of water; but united with carbon or chlorine, the elements of the worid, in the production of earthy or other solid bodies, carbon and

- The presence of ammonia in the atmosphere is reported by $M$. Fresemius, (Athenaum, June $23 r d, 1849$, p. 617 ,) but probably stated in too lo' a proportion, frnm the volatile circulation of that rapour : this is the hydrogen of sotar radiation and nitrogen. chlorine being hydrogen and oxygen in an antithetical condition, or extreme ringes of their primaries, from the latent heat of levity to the latent heat of ponderosity, and from the vitality of sensation to the torpor of insensibility; hence, influencing the forms and characters of the objects created in their various habitats, and being the sources of the various animal temperaments in living beings, and of the variations of the specific gravity of bodies in relation to the earth, air, and water, and of the special temperatures of bodies, ranging between the latent heat of hydrogen and the latent heat of carbon, as developed by oxygen, or condensed by chlorine in the mediality of existence between the loftiest and lowest conditions of matter.

The distinguishing figure of carbon I consider to be the deltoid, a top-heavy ambulator, indicative also of incarceration or sccretiveness, and the figure of chlorine to be the solid disc, at best a giddy tipsy roller, both of which, clogged and heavy from condensation, are illustrative of inertia, and imply corporeal sat uration from the "juniperus Sabina," (Gvyòs $\nu v \mu \phi \varepsilon$ $\Sigma o\left(3 a a_{s}\right.$, from which results, in humanity, a thirst for water, once abundantly supplied, but fat seeks fire."

However, apply ing this theory of characteristic emblems to the choleraic sporules recently discovered, it would appear that they are in form discoid and ovato-discoid, and are consequently chloro-carbonic and hydro-chloric, terraqueous and volatile, as is the earth itself in composition, form, and motion"-."sic ita de, inde locusta."

Without taking into accomst the mutations of matter, and the interdependent combinations of elements essential to the existence of corporeal varietics, or qualitative composition of divers bodies, none of which, however minute or fluid, can be absolutely simple or monogredient, yet the progressive transition from the active levity of youth to the dull decrepitude of age, as well as the ordinary and casual interruptions to a state of health, are undoubtedly assignable to the undue preponderance of those two pernicions elements, carbon and chlorine, hereditary and acquired, demonstrating their pectliarities in the characters of disease, and yet eradicable from the system, and susceptible of sanatory subjection.

I should be glad to associate the figure trinaoria, as " $1 \Psi O \Sigma$ I $\triangle A O \Sigma$," with the armorial ensign of this island, the emblem of motion and progress, which is life as displayed in fleshthe source of which ensign, hidden in the mists of antiquity, has at least been derived from Aspendus, in Pamphylia, as may be seen on the back of a lion in the cabinet of coins of Mr. R.P. Knight, in the British Museum, being of greater antiquity than the Foyptian triade; also, as reported in Mus. Hunter, tab. vii. No. 15 .

Douglas, Isle of Man, Oct. 26, 1849.

P.S.-I have little doubt that the waters of the flooded river Nile, if examined microscopically at some period of the year, will display deltoid atoms in suspension, and which atoms are of a carbonaceous atmospheric formation, and constitute the black and productive soil of that country, teeming also with animal life.

\section{AN INQUIRY INTO THE LAW WHICH GOVERNS THE MORTALITY OF THE PEOPLE OE FNGLAND,}

FOUNDED UPON OFFICIAL RECORDS OF BIRTHS, DEATHS, AND POPULATION, FOR THE LAST SEVENTK YEARS.

By THOMAS ROWE EDMONDS, Ese, ACTEARY TO THK LEGAL AND GENRRAL LIFE ASSURANCE SOCIETY, LONDON.

Withry the last twelvemonth an important addition has been made to the observations which have for their object the determination of the law of mortality prevailing over the population of Fngland. The new observation is founded chiefly on information obtained under the new system of registration of births, deaths, \&c., and is the first fruit of that system so far as concerns investigations of the general law of mortality. This observation has been published in the appendix to the second edition of the ninth annual report of the registrargeneral, and consists of an emumeration according to age, sex and locality, of all the deaths which occurred in England and Wales during the seven years 1838-44, and a corrcsponding enumeration of the numbers living in the year 1841, distin-

- Timbers are fattened from the inflammable exhalations from the graves (carburetted-hydrogen-lax et vita hominum, and ozone is sometimes on the wing. 
guished in the same manner as the deaths. These materials are followed by statements of the resulting annual rates of mortality, deduced from a comparison of the numbers dying and living, distributed, according to locality, in 324 sections, and according to sex, in serenteen gradations of age. This extensive and valuable analysis of the varied mortality of the English population is a manifestation of great labour, directed by superior intelligence, and is highly creditable to the industry and talents of the registrar-general and his coad. jutors.

The only observation previonsly made on the mortality of the English population, according to age, sex, and locality, is that published in the year 1835, of which the results were first communicated to the public in TrE LANCET of December in the same year, (pp. $364 \&$ \& 408.) That observation was founded on returns of the dying in England and Wales during the eighteen years 1813.30 , distributed over the different counties, according to age and sex; and on returns of the living, obtained by enumeration of the whole population in the year 1821, similarly distributed according to age, sex, and locality. The numbers taken to represent the deaths were those entered as burials in the parish registers, increased by a per centage, which was the same at all ages, to cover their estimated deficiency as compared with the actual number of deaths. In making estimates of the deficiency in the registered burials, there was room for great diversity of opinion. These estimates, by the help of the new observation, may now be corrected, and the ralue of the former observation may thus be greatly increased. In columns $1,2,3, \& 4$, of Table I., hereunto annexed, are exhibited the principal results of the two observations for the periods adjacent to the years 1821 and 1841 respectively. The numbers for the period of 1821 are founded on the assumption, that five per cent. is the proper addition to be made to the burials contained in the parish registers in order to obtain the true number of deaths.

There have been made other national observations on the mortality of the Fnglish population, which, commencing with the burials of the year 1781, and with enumerations of the living in the year 1801, were continued to the end of the year 1830. These observations (with the exception of the observation already mentioned) are deficient in the important distinction of the ages, whether of the living or the dying. Notwithstanding this defect, they supply information of considerable value, when they are viewed in combination with the complete observations of 1821 and 1841 . On comparing the numbers of the living with the numbers of the dying, for consecutive periods of five years each, from the beginning of the year 1781 to the end of the year 1830 , it is found that the mortality of the English population was progressively diminishing from the year 1781 to the year 1815, the rate of mortality, at the beginning of the thirty-five years, having been fifty per cent. greater than it was at the end of the period. In the three quinquennial periods-from 1815 to 1830 -there was a progressive increase in the mortality; but the rate of increase subsequent to 1815 was only one-half as great as the rate of decrease previous to 1815 .

From the end of the year 1830 to the beginning of the year 1838 , the burials or deaths of the population of England, either with or without distinction of age, have not been recorded. This interruption of the series of observations has arisen in the transition from one system to a new and improved system-in the transition from the mode of ascertaining the numbers dying, from the burials contained in the parish registers, to the mode of ascertaining the numbers dying by registration, which is compulsory, previously to the burial of any corpse. Under the new Registration Act, the deaths of the population for the year 1838 were observed; but as this Act was not fully carried ont, in other respects, until the beginning of the year 1839 , it will be preferable to reckon the last-mentioned date as the commencement of the new series of deaths and births of the English population. There will then have been observed, at the end of the year 1848 , the deaths of ten years under the new Registration Act. If these deaths be divided into two consecutive periods of five years each, and the rate of mortality in the former conjpared with that of the latter period, it will be found that the rate of increase in the mortality agrees nearly with the rate of in. crease already mentioned for the fifteen years ending with 1830 .

In order further to connect the observed burials of the old series of observations, terminating in 1830 , with the observed deaths of the new series, commencing with 1839 , it is necessary to make an assumption of the proportional addition to be made to the burials of the parish registers, in order to obtain the numbers representing the actual deaths. If the assumption be made that the burials previous to the end of the year 1830 are all to be increased five per cent., in order to obtain the true number of deaths, the old and new series of observations will be in harmony with each other, and form part, apparently, of one continuous series, with regard to the successive quinquennial rates of mortality. The rate of increase in the mortality, during the unobserved interval of eight years-from the end of the year 1830 to the end of the year 1838-will be found identical with the rate of increase observed during the fifteen years before, and during the ten years after, that interval. It may be added, that the average annual mortality, during the five years ending with 1848 , will then be found to be eighteen per cent. greater than the minimum rate of mortality of the English population existing about the year 1815 . [See Table II.]

In addition to the two national observations of the mortality according to age, for the periods adjacent to the years 1821 and 1841 respectively, there has been made, by a private individual, (Dr. Heysham,) a valuable observation on the sec. tion of the English population contained in the town of Carlisle. This observation was made on the population existing during the nine years, $1779-87$, and gave a resulting rate of mortality lower than any before observed, and as low as any since observed, with exception of the mortality below ten years of age. This observation of Dr. Heysham has served as the basis of the table of mortality known as the "Carlisle," which has enjoyed, and still enjoys, a much greater reputation as a standard of mortality than any other table. In agreement with this observation of Dr. Heysham, I have constructed a theoretical table, of which the contained mortality decreases uniformly from birth to the age of eight years, at the rate of thirty-two and a half per cent. (32.39170) for every increase of one year in age; the mortality is then stationary, being at a minimum between the ages of eight and twelve years, and equal to .530359 per cent. per annum; the mortality then increases at the rate of three per cent. (2.99117) from the age of twelve to the age of fifty-five years; after which age the annual rate of increase is eight per cent. (7.96923) until the end of life. This table was published in 1832 , under the designation of "Village" mortality. According to the new observation, for the seven years, 1838-44, the statement made of the mortality, according to age, of the total female population of England, is closely represented by the "Carlisle" observation, and by the "Village" table of mortality-more nearly by the latter than by the former. (See Table V., columns 5 \& 6 ; also Table I., columns $2,4,5, \& 6$.)

The only remaining English observations on mortality useful to mention are those of the Equitable and Amicable As. surance Offices, made on selected lives, (with agcs certified, ) of male persons principally. In these two observations only of selected lives, have the materials been so disposed as to enable an investigator to distinguish the mortality at the same ages of persons differing from each other in the time of membership. The results of such an investigation were communicated to the public in THE LANCET of October, 1837, and September, 1842, (pp. 154 \& 839.) The effect of selection was there shown to be very great, amonnting, in several instances, to fifty per cent. nearly. For example: in the Equitable, at the age of forty-five to fifty years, the number dying in five years, out of 100 living, at the age of forty-five, was shown to vary, from 5.67 for those who had been members less than five years, to 6.59 for those who had been members more than five, but less than fifteen years; and to 8.32 for those who had been members more than fifteen years. The conclusion arrived at, in the latter of the two investigations mentioned, was, that the disturbing effect of selection on the law of mortality would be reduccd to an insignificant amount, if the first five years of membership were excluded, and the law of mor. tality, as derived from observations on members of more than five years' standing, alone regarded. Upon this principle were constructed separatetables, of the experience of the Equitable, and of the Amicable, for intervals of five years, from the age of thirty to ninety years, which was the extent of the obser. vations. From these two tables was then deduced (by taking the mean rates at each age) a single table, representing the combined experience of the Equitable and Anicalle Societies. The table of facts thus formed (founded on 5666 deaths ob. served) was then compared with a theoretical table, of which the superior limit of the period of florescence was fixed at fifty-two years of age, and of which the mortality, at all ages above fifty-five years, was identical with that of the theoretical table published under the designation of "mean" mortality 
and exactly twenty per cent. greater than the mortality contained in the "Village" table at the same ages. The result of the comparison was, that this theoretical table was almost in exact accordance with the facts in the combined experience table, for each of the twelve consecutive quinquennial intervals of age observed. The theoretical table now described (having its superior limit at the age of fifty-two years) is a near representation of the mortality, according to age, of the total male population of England during the seven years, 1838-44, as reported by the registrar-general. [See 'Table

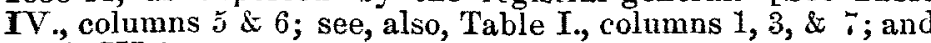
Table VI.]

On comparing the results of the new observation for the seven years adjacent to 1841 with the results of the previous observation for eighteen years adjacent to 1821 , the most remarkable fact which presents itself is the great change which has occurred in the mortality of children, of both sexes, under the ages of five and ten years. For example: in the case of females, during the period adjacent to 1821 , the observed rate of mortality under five years of age was to the observed rate between the ages of twenty and thirty years, in the proportion of 4.22 to .95 , or of 4.44 to 1 , whilst, in the period adjacent to 1841 , the proportion was 6.04 to .94 , or of 6.42 to 1 . If, as is shown in Table $I$., the absolute mortality between the ages of twenty and thirty years was the same at both periods, it will follow that the actual mortality under the age of five years had increased, in the interval of twenty years, (from 1821 to 1841 ,) in the high proportion of 6.4 to 4.44 , which is equivalent to an increase of forty-four per cent.

This increase in the mortality of children is connected (as cause or effect) with the extension of the period over which the constant of infancy (32.3917) presides, as the regulator of the decrease of the mortality. In all observations on human mortality, the rate at birth (or a few weeks after) uniformly decreases thirty-two and a half per cent. for each year's advance in age, for a period of which the termination is variable between the limits of seven and ten years of age. Previously to the publication of the English observation for the eighteen years adjacent to 1821, there was not (I believe) known to the public any observation which showed an earlier termination of the infancy period than at nine years of age. By that observation, it was shown that the termination of the infancy period for the total population was as early as eight years and one month for males, and seven years and seven months for females. According to the present observation for the seven years adjacent to 1841 , the termination of the infancy period was at eight year's and eight months for males, and at eight years and two months for females, the extent of the period for both sexes having been increased by seven months nearly in the interval from 1821 to 1841 .

In all observations on human mortality according to age, the mininum mortality is found to be attained at the termination of the infancy period; this minimum is generally continued for about five years, perhaps to the age of puberty. In all the sections of the English population observed at the two periods of 1821 and 1841 respectively, the minimum nortality occurs at the interval from ten to fifteen years of age, the mortality at that age being always less than that of any preceding or succeeding specified interval of age. The minimum mortality (at the age mentioned) of the total population of the period 1811 is observed to be eleven per cent. greater than the miuimum for the period of 1821 , whilst the mortality at birth, and five years after, had become forty-four per cent. greater, as before stated. In the different sections of the English population, the variations in the mortalities under five years of age are considerably greater than the variations in the minima mortalities between the ages of ten and fifteen years. The annual rates of mortality between the ages of 0 and five years vary in different places from four per cent. to fourteen per cent., whilst the rariations in the minima rates of mortalities are only from 48 per cent. to $.6 \pm$ per cent. This relation in the mortality at the two intervals is a con sequence of the general law, that when the mortality at birth in any ulace is very great, the length of the period over which the constant of intancy presides is also proportionally great.

The two enumerations, according to ages, of the total living population of England, in the years 1821 and 1841 re spectivelr, afford some valuable information, independently of the chief information supplied by the comparison of the living with the dying at corresponding intervals of age. The mortality of the people of a large coutry is ascertainable by two or more correct enumerations of the living according to age, without any direct knowledge of the deaths. If the number living between thirty and forty years of age be ascertained at one enumeration, and at another enumeration, taking place exactly ten years after the first, the number living between the ages forty and fifty be ascertained, we shall then know the proportion connecting together the number living at the age of thirty and forty with the number surviving to ages ten years greater, which will indicate the law of mortality for one decennial interval of age. By proceeding upon the same principle at other intervals of age, the mortality of auy nation in Europe might probably be ascertained without any con siderable amount of error if the enumeration in classes accord. ing to age could be made with exactness. It is only in countries whereof the balance of migration is high that the above principle would lead to uncertain results. With regard to England, the principle appears to be applicable, there being up to the period of the last observation, no ground for supposing that England loses by emigration more than she gains by immigration.

The total female population of England at the middle of the year 1821 amounted to $6,146,020$, classified in intervals of age not exceeding ten years each. According to the table of "Yillage" mortality (limits at eight and fifty-five years), the survivors from the above population at the expiration of twenty years would have amounted to $4,445,540$. If there had been no balance of gain or loss by migration, and if the above table correctly indicated the mortality, the last-mentioned number would represent the number living of females above the age of twenty at the middle of the year 1841. By actual enumeration the number then ascertained to be living was $4,473,930$, which differs from the calculated number by 28,390 only, which is about one-half per cent. on the amounts compared.

On comparing columns $4 \& 5$ of Table III., it will be seen that whilst the numbers calculated agree with the numbers enumerated in the aggregates living or surviving above twenty years of age, there is a variation in some cases of considerable amount in the separate decennial or quinquennial intervals of age. Taking decennial intervals of age, it will be seen that the chief variation is between the ages of twenty and thirty years, when the numbers by enumeration are seven per cent. greater than the numbers obtained by calculation The excess in number is, however, very nearly compensated in amount by an equal dafect in numbry distributed over the succeeding three decennial intervals of age from thirty to sixty years. The explanation of this variation appears to lie in the incorrectness of the enumeration, arising from the disposition of the people to underrate their ages: the numbers contained in the class between twenty and thirty years of age being unduly increased at the expense of the numbers in the classes between thirty and sixty years of age. At ages above sixty, the numbers of the enumeration are sufficiently in accord ${ }^{*}$ with the calculated numbers, witl the exception of the interval between seventy and eighty years, when the enumerated numbers are considerably in excess. This variation is probably due (in part) to the deficiency of the numbers returned in 1821 as living between fifty and sixty years; for these being deficient, the calculated numbers, as surviving between seventy and eighty years in 1841, will be proportionally deficient.

One of the chief and most durable characteristics of the porulation of a country is its rate of increase. In the United States of North America, for more than half a century, the rate of increase has been thirty per cent. every ten years, (exclusive of the increase from immigration.) Next in rank is England, with a rate of increase, for a similar period, of fifteen per cent. every ten years. Then comes France, and other continental nations of Europe, having an increase of about seven per cent. every tew years. Under a given law of mor tality, the form of the curve representing the numbre living at successive intervals of age, varies in a definite manner according as the rate of increase varies. The proportion of the living in the early ages of life is greatest when the rate of increase is greatest. In columns $1 \& 2$ of Table III. are represented two populations of 100,000 each, distributed as they would be under the operation of the "Tillage" table of mortality, with a rate of increase which in one case is nil, and in the other case is equal to fiftecn per cent. every ten years. In the columns $3 \& 4$ of the same table is represented the distribution of the female population of England, ascertained by enumerations in the years 1821 and 1811 , respec. tively. On a comparison of columns 1 \& 2 , it will be observed how great is the difference, in the form of distribu- 
tion, between a population which is stationary and a population which is increasing fifteen per cent. every ten years. On comparing together columns $2,3, \& 4$, it will be seen that they all nearly resemble each other, when large intervals of age are compared. On this resemblance or coincidence we may found the conclusion, that if the "Village" table has been for a very long period a true representation of the mortality; in that case, the increase of the population, in successive decennial gradations of age, has been uniform, and nearly equal to fifteen per cent. for a period little short of a century. At all ages above fifty years the distribution of the population in 1821 was nearly the same as the distribution in 1841 ; so that the origin of the existing rate of increase was as remote in 1821 as it was in 1821 - that is, in other words, the rate of increase has been perpetual, so far as can be shown by the two observations.

The increase in the greater number of the consecutive decennial classes (according to age) of the Fnglish population is nearer fourteen than fifteen per cent.; the higher proportion appears to be temporary, and to have arisen from the ten years, 1811-20, when the mortality was at a minimum, and the excess of births over deaths at a maximum. Assuming that the characteristic and more permanent rate of increase of the English population as fourteen per cent. every ten years, it would follow that, under a given constant law of mortality, the births would increase at the same rate in a long period of half a century or more. From observation, it is found that the births of the English population, from 1800 to 1848 , or in forty eight years, have increased on an average, at the rate of fourteen and a half per cent. in ten years. In the marriages from 1755 to 1845 we have a tolerably correct idea of the increase of births in these ninety years, since the births generally bear a fixed proportion to the marriages in the same population. The decennial rate of increase of the marriages, and, it is to be presumed, of the births also, was only eleven per cent. in the ninety years. The difference (three per cent.) between this rate of increase in the births, and fourteen per cent., the rate of increase in the successive decennial stages of the population, remains to be accounted for. This excess of increase in the population over that of the births is probably the effect of a decreasing mortality of children for a long period before the year 1815, such decrease having continued much longer than the increase in the mortality of children which since 1815 has been in operation.

In the account of births for all England there is a large deficiency in the recent returns under the new Registration Act, as well as in the previous returns obtained from the parish registers of baptisms. In both cases the registration is voluntary, the parents being free to say whether their children at birth shall be baptized or registered, both or neither. The amount in which the returns of births or baptisms are deficient, is, however, capable of being ascertained with considerable precision from the same materials which serve to determine the mortality of the population. In a stationary population, if the law of mortality under the age of ten years be known, and if the actual number living under that age be also known, in that case the exact number of annual births is known from calculation. In practice, with a population having a known rate of increase, the actual number of births may be ascertained on similar principles with similar precision. The only sources of inaccuracy are, possible defects in the returns of the numbers living, and occasional variations from the average rate of increase of the births.

The average annual births of females in England, at the years 1821 and 1841 respectively, may be obtained by calculation from the enumerations of the living under ten years of age in those years, and from the contemporary rate of mortality observed. The actual numbers so obtained, when converted into numbers proportional to a given number of females living at all ages, are found to represent average annual rates of birth equal to 3.46 and 3.39 per cent. at the respective years 1821 and 1841 . These rates of birth, when compared with the rate of baptisms from the parish registers previous to the end of the year 1830 , and with the rate of registered births under the new system, indicate deficiencies which are just twice as great in the former as in the latter case. In order to obtain the true number of births, there is required an increase of two ninth parts of the baptisns, and an increase of one ninth part of the births registered under the new Act. In Table II. column 2, the numbers representing the true number of births of females in England from the year 1801, have been obtained by additions for deficiencies as now indicated. In the same table, the numbers in column 3 representing the deaths of females in all England, the numbers for the period antecedent to the end of the year 1830 have been obtained by adding five per cent. to the registered burials; but the numbers for the succeeding periods have been left unchanged, it being presumed that there is no deficiency in the deaths registered under the new system. The differences between the numbers in columns $2 \& 3$, represent the excess of births over deaths, and agree very nearly with the increase of the female population at the corresponding periods ascertained by enumeration.

In order that the observation for the eighteen years, 1813-30, may be in accordance with the observation for the seven years, 1838.44, it is necessary to diminish considerably the estimate of deficiency hitherto made with regard to the burials contained in the parish registers previously to the end of the year 1830 . The estimates of deficiency made by dif. ferent persons have varied from eight and a half to seventeen per cent., as the requisite addition to be made to the registered burials. The proper addition, grounded upon information now presented, is less than any estimate hitherto formed, and amounts to five per cent. only. With this addition, the increasing mortality of the three consecutive quinquennial periods, from 1815 to 1830 , would be (as already stated) in continuity and accordance with the increasing mortality observed in the two consecutive quinquennial periods terminating with 1848 , which have elapsed since the Registration Act came into full operation. With this amount of correction, the mortality at all ages above twenty years would be the same for the eighteen years adjacent to 1821 , as for the seven years adjacent to 1841 , which mortality for females is that of the "Carlisle" or "Village" table. Also, this mortality, conjoined with the female population as distributed in decennial intervals of age in 1821, is found to represent a total number of survivors at ages twenty years greater, which agrees exactly with the numbers obtained by enumeration in 1841, as has been already stated. Moreover, the distribution of the total female population according to age. at the two enumerations of 1821 and 1841 respectively, coincided substantially with the distribution of a population subject, for a long period of years, to the "Village" law of mortality, and to an increase of fifteen per cent. every ten years, (which is the rate of increase indicated by the enumerations from 1801 to 1841.) It is also deserving of mention, that if a higher deficiency than five per cent. be assumed, and if it be also assumed that there is ito deficiency in the deaths reported under the new Registration Act, it will ensue that the mortality of the English population during the twenty years, 1821 to 1841 , had been decreasing at all ages above twenty years, whilst it had been increasing at all ages under twenty years-a course of progressive change in the mortality of which there is no example, and which is highly improbable.

The high estimates previously made of the deficiencies of the burials contained in the parish registers, may, in a great measure, be ascribed to the incredulity with which the results indicated by the alleged facts were received. The actual mortality of the females of all England, during the ten years 1811-20, has been shown, in Table II., to have been 1.85 per cent. per annum, or one out of every fifty.four living, a mortality lower than was consistent with any table of mortality then extant, and which is now only capable of a full explanation. The mortality under the age of five years was equal, at that time, to one half only of the lowest mortality previously exhibited, in the Carlisle or any other table, at the same age.

The proportion of deaths unentered in the parish registers, collected from all the estimates in numbers of the clergymen making the returns, amounted to four and a quarter per cent. of the registered burials. This estimate (though near the truth) was regarded as inapplicable to the whole of England, because a considerable (unknown) proportion of the parishes into which England is divided supplied no estimate of deficiency in the burials. It was assumed, without any specifio ground, that if all the clergy who were silent as to deficiencies had also made est imates, in that case the total proportionate deficiency would have been at least doubled, or would have amounted to notless than eight and a half per cent. Noallowance was made for the probability, that the clergy making the returns were partakers in common with the public, in the disbelief of the extraordinary low mortality, resulting from the previously published returns, which disbelief could hardly fail to bias their minds towards the exaggeration of the estimates of deficiency which they would have otherwise made.

In one respect, the estimates of the clergymen of the various parishes have been very wide of the truth-viz., in the relative numbers of the unentered births and the unentered deatho. 
The aggregate of the estimated numbers of unentered births on the assumption, that the unentered births were to the unand deaths, for the eighteen years, 1813-30, were stated to be in the proportion of two to one nearly, including London, and in the proportion of three to one exclusive of London. The proportion should have been that of seven to one for all England; at least, this is the true proportion, if the reasons adduced in support of the correctness of Table II. be held satisfactory. In vol. ii. of The Laxcet for 1835, (pp. 364, 408,) which contains the investigation of the English observation of the eighteen years, 1813-30, the numbers representing the annual rates of mortality, at different ages, are founded entered deaths in the proportion of three to one, and that the excess of the actual births over the actual deaths was equal to the increase of the population in the same period. This assumption, from information now obtained, is to be corrected by the substitution of the proportion seven to one, instead of three to one. The effect of such substitution is to reduce the numbers then given by one twelfth part, at erery age of life. It is by such reductions that the numbers in colunns 1 \& 2 of the annexed Table $I$. have been obtained.

(To le continued.)

\section{TABLE I.}

TABLE, showing, for each of twelve intervals of Age, and for each Sex, the Mortality per cent. per annum of the Populations of ENGLAND and of SWEDEN, for two periods each; exhibiting also, for Comparison, three Theoretical Tables, of which the Mortalities at every Age are in the proportions of $5,6, \& 7 \frac{1}{2}$ respectively.

\begin{tabular}{|c|c|c|c|c|c|c|c|c|c|c|c|c|}
\hline \multirow{2}{*}{ AGE. } & \multicolumn{2}{|c|}{$\begin{array}{l}\text { ENGLAND, } 18 \text { Years. } \\
1813-1830 .\end{array}$} & \multicolumn{2}{|c|}{$\begin{array}{l}\text { ENGLAND, } 7 \text { Years. } \\
1838-1844\end{array}$} & \multirow{2}{*}{$\begin{array}{c}\text { CARLISLE, } \\
9 \text { Years. } \\
1779-1787 . \\
\text { Both Sexes. }\end{array}$} & \multicolumn{3}{|c|}{$\begin{array}{l}\text { Theoretical TABies, } \\
\text { Limits at } 8 \text { \& } 55 \text { Years of Age. }\end{array}$} & \multicolumn{2}{|c|}{\begin{tabular}{|c|} 
SWEDEN \& FINLAND, \\
41 Years. \\
$1755-179$.
\end{tabular}} & \multicolumn{2}{|c|}{$\begin{array}{l}\text { SWEDEN, } 30 \text { Years. } \\
1811-1840\end{array}$} \\
\hline & Males. & Females. & Males. & Females. & & Village. & Mean. & City. & Males. & Females. & Males. & Females. \\
\hline $\begin{array}{r}0-5 \\
5-10 \\
10-15\end{array}$ & $\begin{array}{r}4.90 \\
.66 \\
.46\end{array}$ & $\begin{array}{r}4.22 \\
.61 \\
.48\end{array}$ & $\begin{array}{r}7.07 \\
.93 \\
.50\end{array}$ & $\begin{array}{r}6.04 \\
.90 \\
.55\end{array}$ & $\begin{array}{r}8.23 \\
1.02 \\
.54\end{array}$ & $\begin{array}{r}5.54 \\
.82 \\
.54\end{array}$ & $\begin{array}{r}6.70 \\
.99 \\
.65\end{array}$ & $\begin{array}{r}8.47 \\
1.24 \\
.82\end{array}$ & $\begin{array}{r}9.24 \\
1.45 \\
.72\end{array}$ & $\begin{array}{r}8.28 \\
1.34 \\
.66\end{array}$ & $\begin{array}{l}7.28 \\
.83 \\
.52\end{array}$ & $\begin{array}{r}6.27 \\
.78 \\
.49\end{array}$ \\
\hline $\begin{array}{l}15-20 \\
20-30 \\
30-40 \\
40-50\end{array}$ & $\begin{array}{r}.66 \\
.93 \\
1.05 \\
1.37\end{array}$ & $\begin{array}{r}.70 \\
.95 \\
1.14 \\
1.37\end{array}$ & $\begin{array}{r}.70 \\
.94 \\
1.09 \\
1.45\end{array}$ & $\begin{array}{r}.79 \\
.94 \\
1.13 \\
1.32\end{array}$ & $\begin{array}{l}.64 \\
.75 \\
1.06 \\
1.43\end{array}$ & $\begin{array}{l}.62 \\
.78 \\
1.05 \\
1.40\end{array}$ & $\begin{array}{r}.75 \\
.93 \\
1.25 \\
1.68\end{array}$ & $\begin{array}{l}.94 \\
1.17 \\
1.57 \\
2.10\end{array}$ & $\begin{array}{r}.70 \\
.99 \\
1.23 \\
1.82\end{array}$ & $\begin{array}{r}.65 \\
.83 \\
1.15 \\
1.54\end{array}$ & $\begin{array}{r}.54 \\
.90 \\
1.31 \\
1.96\end{array}$ & $\begin{array}{r}.53 \\
.73 \\
1.06 \\
1.42\end{array}$ \\
\hline $\begin{array}{r}50-60 \\
60-70 \\
70-80 \\
80-90 \\
\text { Above } 90\end{array}$ & $\begin{array}{r}2.14 \\
4.15 \\
9.28 \\
20.82 \\
33.93\end{array}$ & $\begin{array}{r}1.98 \\
3.78 \\
8.88 \\
19.67 \\
34.09\end{array}$ & $\begin{array}{r}2.26 \\
4.28 \\
9.22 \\
20.11 \\
36.53\end{array}$ & $\begin{array}{r}1.98 \\
3.79 \\
8.42 \\
18.32 \\
34.58\end{array}$ & $\begin{array}{r}1.83 \\
4.12 \\
8.30 \\
17.56 \\
28.44\end{array}$ & $\begin{array}{r}2.01 \\
4.05 \\
8.46 \\
17.16 \\
33.45\end{array}$ & $\begin{array}{r}2.40 \\
4.83 \\
10.04 \\
20.18 \\
39.85\end{array}$ & $\begin{array}{r}2.99 \\
5.99 \\
12.36 \\
24.53 \\
47.20\end{array}$ & $\begin{array}{r}2.82 \\
5.25 \\
10.53 \\
20.68 \\
37.27\end{array}$ & $\begin{array}{r}2.25 \\
4.58 \\
10.17 \\
19.99 \\
37.28\end{array}$ & $\begin{array}{r}3.09 \\
5.66 \\
11.81 \\
25.63 \\
42.15\end{array}$ & $\begin{array}{r}2.30 \\
4.72 \\
10.54 \\
23.01 \\
39.72\end{array}$ \\
\hline All ages... & 1.99 & 1.90 & 2.27 & 2.10 & 2.50 & ... & ... & ... & 2.91 & 2.67 & 2.56 & 2.28 \\
\hline
\end{tabular}

\section{TABLF II.}

TABLE, showing, for the Female Population of England, in periods of Five Years, from the beginning of the year 1781 to the end of the year 1848, (with an interruption of eight years,) the Annual Rates of Births and Deaths per cent. (The true number of Deaths have been obtained by adding five per cent. to the Burials recorded in the Parish Registers for the fifty years ending with 1830 The true number of Births have been obtained by adding two ninth parts to the Baptisms recorded in the Parish Registers previous to the end of the year 1830 and by adding one ninth part to Births registered in the ten years beginning with 1839.)

\begin{tabular}{|c|c|c|c|c|c|}
\hline $\begin{array}{l}\text { Periods of } \\
\text { five years. }\end{array}$ & $\begin{array}{l}\text { Female popu- } \\
\text { lation at be- } \\
\text { ginning of } \\
\text { each period of } \\
\text { five years. }\end{array}$ & $\begin{array}{l}\text { True } \\
\text { births of } \\
\text { females. }\end{array}$ & $\begin{array}{l}\text { True } \\
\text { deaths of } \\
\text { females. }\end{array}$ & $\begin{array}{l}\text { Result- } \\
\text { ing rate } \\
\text { of } \\
\text { Births. }\end{array}$ & $\begin{array}{l}\text { Result- } \\
\text { ing rate } \\
\text { of } \\
\text { Deaths }\end{array}$ \\
\hline $1781-1785$ & $3,604,900$ & & 497,705 &. & 2.68 \\
\hline & & & & & \\
\hline & 4,06 & & & .. & 2.44 \\
\hline & & $\because \quad \because$ & & & 2.25 \\
\hline $\begin{array}{l}1801 \\
1806\end{array}$ & 4,616 & 832,603 & & 3.49 & 2.13 \\
\hline $\begin{array}{l}1806-1810 \\
1811-181\end{array}$ & & 891,010 & & 3.50 & 2.00 \\
\hline $1811-1815$ & & 947,418 & & 8 & 1.85 \\
\hline $\begin{array}{l}1816-1820 \\
1821-1825\end{array}$ & & 996,540 & & & 1.84 \\
\hline $\begin{array}{l}1821-1925 \\
1826-1930\end{array}$ & $6,113,600$ & $1,101,550$ & 605,914 & 3.47 & 1.91 \\
\hline $\begin{array}{l}1826-1930 \\
1831-1835\end{array}$ & $\begin{array}{l}\mathbf{6}, 582,300 \\
7,087,200\end{array}$ & $1,142,511$ & 666,478 & 3.34 & 1.95 \\
\hline 1839 & & 1,3 & & $3.39 *$ & 2.10 \\
\hline $\begin{array}{l}1844-1848 \\
1849-1853\end{array}$ & $8,418,200$ & $1,495,288$ & 94,984 & $\mathbf{3 . 4 3}$ & 2.17 \\
\hline & & & & & \\
\hline
\end{tabular}

- At years 1821 and 1841 , the annual rates of births, from enumerations of living and dying under ten years of age, were 9.16 and 3.39 per cent. reopectively.

\section{TABLE III}

TABLE, in which the Female Populations of England, ascertained by enumeration in the years 1821 and 1841 respectively, are compared with the results of the Table of Village Mortality (limits at eight and fifty-five years of age), when the population is increasing at the rate of fifteen per cent. every ten years, and when the numbers living at one enumeration are deduced from the numbers twenty years younger at the previous enumeration.

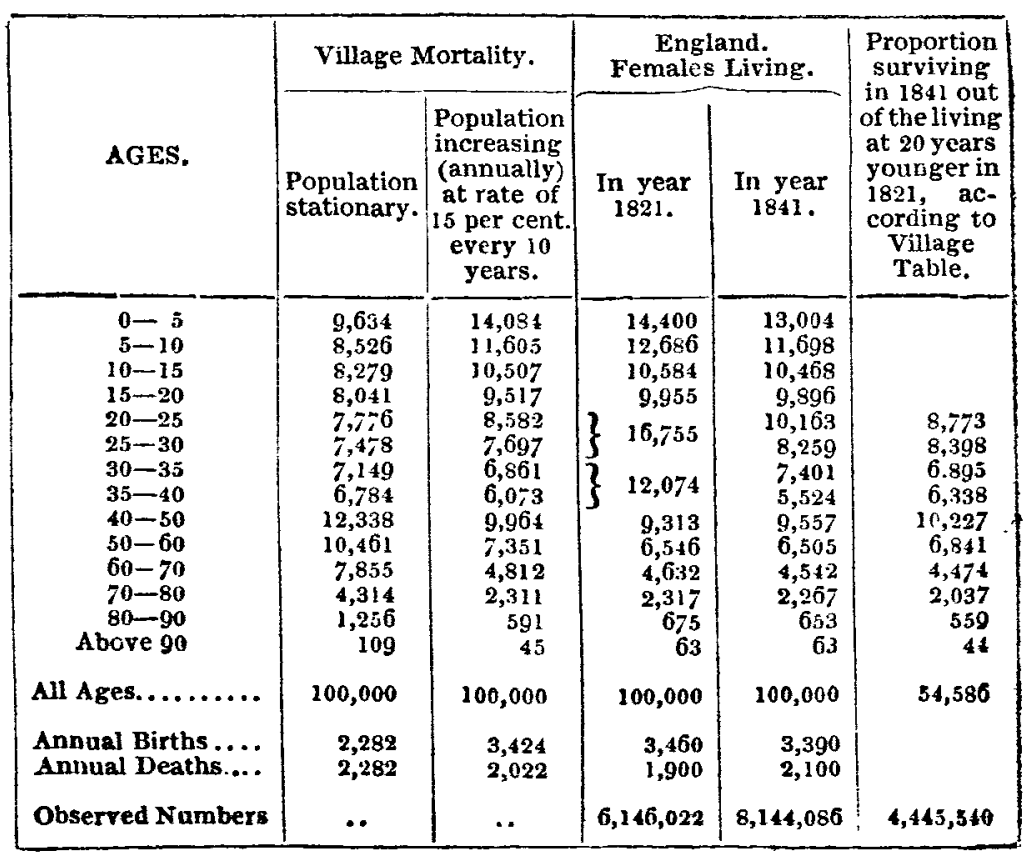

